\title{
Substâncias isoladas das folhas de Bauhinia microstachya (Raddi) Macbr. (Caesalpiniaceae)
}

\author{
Bianco, E.M.; Santos, C.A.M* \\ Laboratório de Farmacognosia, Departamento de Farmácia, \\ Universidade Federal do Paraná, Curitiba, PR.
}

\begin{abstract}
RESUMO: Neste trabalho é relatado o isolamento de três substâncias das folhas de Bauhinia microstachya (Raddi) Macbr., Caesalpiniaceae, incluindo dois constituintes isolados pela primeira vez nesta espécie, a vitexina e o hidrocarboneto hexatriacontano. As estruturas desses compostos foram estabelecidas através de estudos de RMN- ${ }^{1} \mathrm{H} 1 \mathrm{D}, 2 \mathrm{D}$ e EM.
\end{abstract}

Unitermos: Bauhinia microstachya, vitexina, galato de metila, hexatriacontano.

ABSTRACT: Substances isolated from Bauhinia microstachya (Raddi) Macbr. Caesalpiniaceae) leaves. It is reported the isolation of three compounds from leaves of Bauhinia microstachya (Raddi) Macbr., Caesalpiniaceae, including two new constituents in this species, vitexin and the hydrocarbon hexatriacontane. Their structures were established by extensive $1 \mathrm{D}$ and $2 \mathrm{D}{ }^{1} \mathrm{H}$ NMR and MS spectral studies.

Key words: Bauhinia microstachya, vitexin, methyl gallate, hexatriacontane.

\section{INTRODUÇÃO}

Entre as inúmeras espécies vegetais de interesse medicinal estão as plantas do gênero Bauhinia, pertencentes à família Caesalpiniaceae, as quais podem ser encontradas, principalmente, nas áreas tropicais do planeta. Estudos fitoquímicos e farmacológicos realizados com essas plantas revelaram que os principais metabólitos secundários por elas produzidos são em geral flavonóides, triterpenóides e glicosídeos esteroidais. No Brasil, as plantas do gênero Bauhinia são conhecidas como pata-de-vaca, unha ou casco-de-boi (FORTUNATO, 1986). Folhas, caules e raízes de $B$. forficata, $B$. variegata, $B$. splendens, $B$. manca e $B$. rufescens são amplamente utilizados, em forma de chás e outras preparações, para o tratamento de várias enfermidades, principalmente, infecções, processos dolorosos e diabetes (VOLPATO et al., 1999; SILVA et al., 2002; PEPATO et al., 2002; GONZALEZ-MUJICA et al., 2003). Além das espécies citadas, muitas outras são usadas, indiscriminadamente, como medicinais, tais como B. rufa, B. monandra, $B$. 
holophylla e $B$. smiliciana; entretanto, pouco se sabe a respeito dos seus constituintes químicos (SILVA; CECHINEL-FILHO, 2002).

Muitas espécies do gênero Bauhinia têm sido estudadas com relação à sua constituição química, e várias classes químicas e substâncias de interesse medicinal foram isoladas e relatadas nesses últimos anos, embora muito pouco se conheça a respeito do potencial farmacológico desses compostos. Foi demonstrado que os extratos $\mathrm{EtOH} / \mathrm{H}_{2} \mathrm{O}$ e AcOEt de $B$. splendens apresentaram pronunciados efeitos analgésicos, quando analisados no modelo de dor causada pelo ácido acético a 0,6\%, em camundongos (WILLAIN-FILHO et al., 1997). Estudos realizados com folhas de B. microstachya (MEYRE-SILVA et al., 2001) demonstraram a presença de canferol3-O-ramnosil, quercetina-3-O-ramnosil, miricetina-3-O-ramnosil e galato de metila. Nesse estudo foi, também, demonstrada uma relevante atividade analgésica para o extrato metanólico das folhas, tendo sido sugerido que os compostos fenólicos poderiam estar associados à essa analgesia, sendo necessário maiores estudos para comprovar tal atividade.

Neste trabalho é relatado o isolamento de três substâncias das folhas de B. microstachya: galato de metila, vitexina e hexatriacontano, sendo que as duas últimas foram isoladas pela primeira vez, dessa espécie vegetal.

\section{MATERIALE MÉTODOS}

\section{Material vegetal}

Folhas e caules de Bauhinia microstachya (Raddi) Macbr. $(4,2 \mathrm{~kg})$ foram coletados em fevereiro de 2002 em Morretes-PR. A espécie foi identificada pelo Dr. Gert G. Hatschbach, e uma exsicata, foi depositada no Herbário do Museu Botânico Municipal de Curitiba, sob o número de registro MBM 264.361.

\section{Métodos gerais}

Para as cromatografias em camada delgada (CCD) foram utilizadas cromatoplacas em gel de sílica $F_{254}\left(\right.$ Merck $\left.^{\circledast}\right)$ e as cromatografias em coluna foram realizadas usando como fases estacionárias gel de sílica 60 70-230 mesh e 230-400 mesh (Merck ${ }^{\circledR}$ e Aldrich $^{\circledR}$ ) e Sephadex ${ }^{\circledR}$ LH20 (Pharmacia ${ }^{\circledR}$ ). Os espectros de UV foram obtidos em espectrofotômetro Shimadzuâ, modelo 1601; os espectros de ressonância nuclear magnética em espectrômetro DRX-400 ${ }^{\circledR}, 400 \mathrm{MHz} e$ ARX-200 ${ }^{\circledR}, 200 \mathrm{MHz}$. A cromatografia gasosa acoplada a um espectômetro de massa (CG-EM) foi realizada em cromatógrafo gasoso $\mathrm{HP}^{\circledR} 6890$, utilizando coluna capilar de fenilmetilsiloxano HP5MS como fase estacionária, com injetor automático, gás de arraste Hélio, volume de injeção 0,2 $\mathrm{ml} e$ temperatura do injetor $250^{\circ} \mathrm{C}$. Os solventes foram destilados e purificados antes do uso (ARMAREGO; PERRIN, 2000).

\section{Obtenção dos extratos e frações}

Folhas $(1 \mathrm{~kg})$ foram secas $\left(45^{\circ} \mathrm{C}, 48 \mathrm{~h}\right)$, moídas e extraídas com solventes de polaridade crescente ( $n$-hexano, clorofórmio e etanol 90\%), fornecendo os extratos EHF, ECF e EBEF, respectivamente. $O$ extrato EBEF foi submetido a desclorofilação e deslipidificação por meio de agitação em água gelada (1:8), sendo denominado então de EEF. Este extrato hidrofílico foi submetido à partição com diclorometano e acetato de etila fornecendo as frações diclorometano (FDF), acetato de etila (FAEF) e aquosa (FAQF) (Figura 1).

Rev. Bras. Farmacogn., V. 13, n. 2, jul.-dez. 2003. 


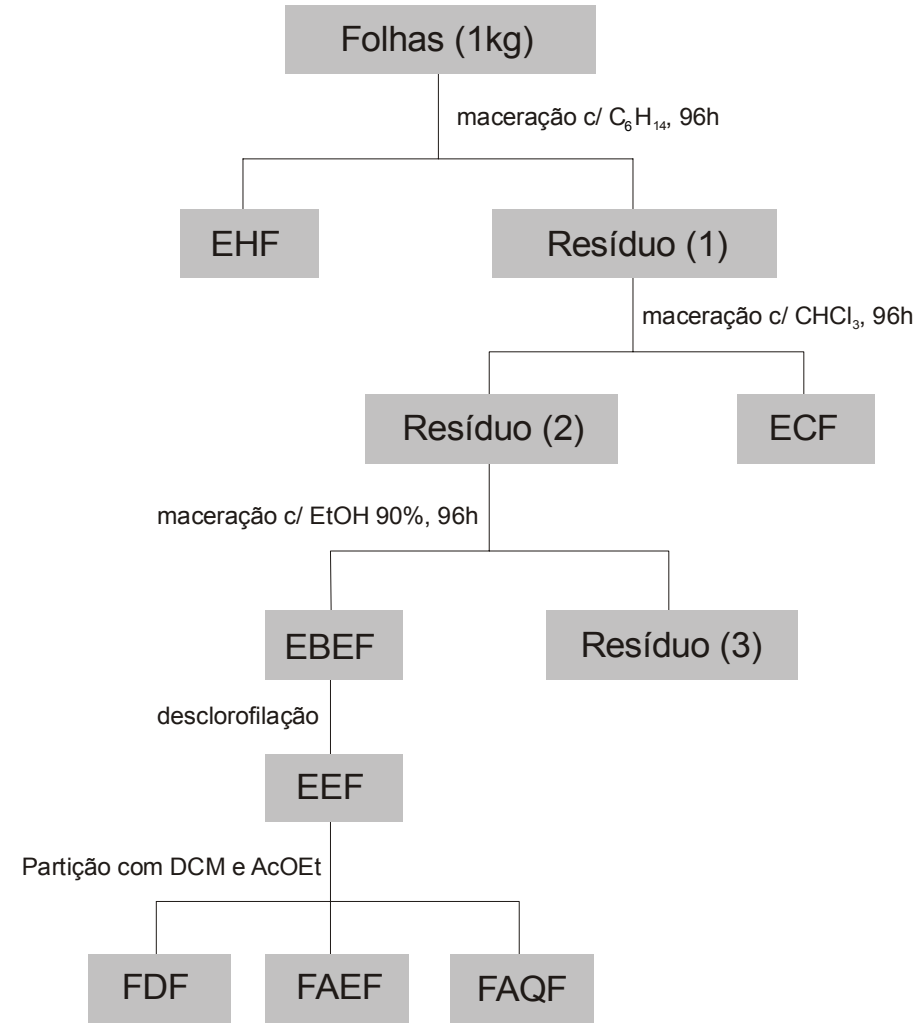

Figura 1. Obtenção dos extratos e frações a partir das folhas de Bauhinia microstachya (Raddi) Macbr. (Caesalpiniaceae)

\section{Isolamento da vitexina}

Aproximadamente $26 \mathrm{~g}$ da fração FAEF foram suspensos em $\mathrm{Me}_{2} \mathrm{CO}$ ocorrendo a precipitação de um sólido amarelado $(40 \mathrm{mg})$ que foi separado por filtração. O filtrado foi submetido à cromatografia em coluna de gel de sílica e eluída com solventes na forma de gradiente de polaridade crescente $\left(\mathrm{C}_{6} \mathrm{H}_{14}, \mathrm{C}_{6} \mathrm{H}_{14}-\mathrm{CHCl}_{3}(1: 1), \mathrm{CHCl}_{3}, \mathrm{CHCl}_{3}-\mathrm{AcOEt}\right.$ (1:1), AcOEt, AcOEt-MeOH (1:1) e $\mathrm{MeOH}$ ). As frações eluídas com metanol foram reunidas, secas e dissolvidas em clorofórmio, de onde precipitou um sólido amarelo amorfo, que foi filtrado a vácuo e lavado sucessivas vezes com $\mathrm{C}_{6} \mathrm{H}_{14}$ e $\mathrm{CHCl}_{3}$. O precipitado seco resultou em um sólido amarelo-claro (3 mg), que mostrou estar puro por CCD.

\section{Isolamento do galato de etila}

Parte da fração FAEF $(5 \mathrm{~g})$ foi submetida à cromatografia em coluna de gel de sílica, eluída com solventes na forma gradiente de polaridade crescente $\left(\mathrm{C}_{6} \mathrm{H}_{14}, \mathrm{C}_{6} \mathrm{H}_{14}-\mathrm{CHCl}_{3}(1: 1), \mathrm{CHCl}_{3}, \mathrm{CHCl}_{3}-\right.$ $\mathrm{MeOH}(9,5: 0,5), \mathrm{CHCl}_{3}-\mathrm{MeOH}$ (9:1), $\mathrm{CHCl}_{3}-\mathrm{MeOH}$ (8:2), $\mathrm{CHCl}_{3}-\mathrm{MeOH}$ (7:3) e MeOH). Dessa forma, 85 frações $(10 \mathrm{ml})$, monitoradas por $\mathrm{CCD}$, foram coletadas e as frações 13-45 $\left(\mathrm{CHCl}_{3}-\mathrm{MeOH} 8: 2\right)$ foram reunidas por semelhança, fornecendo um sólido alaranjado $(2 \mathrm{~g})$. Parte desse $(1 \mathrm{~g})$ foi solubilizado em metanol e cromatografado em CCD preparativa com acetato de etila, obtendo-se cinco bandas e, pela proximidade de duas delas, não foi possível sua total separação; sendo assim, essas bandas foram raspadas da placa, suspensas em metanol e o material obtido foi 
cromatografado em coluna de Sephadex ${ }^{\circledR} \mathrm{LH} 20$ com etanol, resultando no isolamento de um sólido branco-amarelado (1,6 mg), que mostrou estar puro por CCD.

\section{Isolamento do hexatriacontano}

Os extratos EHF e ECF, quando cromatografados por CCD, utilizando $\mathrm{C}_{6} \mathrm{H}_{14}$-AcOEt (1:1) como fase móvel e vanilina sulfúrica como solução reveladora, mostraram-se semelhantes quanto à composição química. Esses extratos EHF $(9 \mathrm{~g})$ e ECF $(4 \mathrm{~g})$ foram reunidos e cromatografados em coluna de gel de sílica, eluída com solventes na forma de gradiente de polaridade crescente. As frações 3-20 (15 ml cada) (éter de petróleo) foram reunidas por semelhança, secas, solubilizadas em $\mathrm{C}_{6} \mathrm{H}_{14} \mathrm{e}$, através da adição de etanol, ocorreu precipitação de um sólido, que foi filtrado e lavado com porções de etanol e metanol, obtendo-se um sólido branco (32 mg), que mostrou estar puro por CCD.

\section{RESULTADOS E DISCUSSÃO}

\section{Identificação da vitexina}

O composto apresentou-se na forma de sólido amarelo-claro e o espectro de UV mostrou bandas de absorção em $\lambda_{\max }(\mathrm{MeOH}) 226,270$ e $332 \mathrm{~nm}$ e deslocamento batocrômico pela adição de $\mathrm{NaOH} 280,329$ e $394 \mathrm{~nm}$. O espectro de infravermelho mostrou uma banda larga em $v_{\max }$ $3350 \mathrm{~cm}^{-1}$, característico de grupos hidroxilas, absorção de carbonila conjugada e com ligação de hidrogênio intramolecular em $1665 \mathrm{~cm}^{-1}$ e sinais de tamanho médio entre 1600 e $1500 \mathrm{~cm}^{-1}$, indicando também a presença de grupos aromáticos nesta molécula.

As informações que levaram à elucidação da estrutura foram obtidas dos experimentos de ressonância nuclear magnética de prótons, cujos espectros indicaram um padrão conhecido para 4',5,7-tri-hidróxiflavona (MABRY; MARKHAM; THOMAS, 1970). O espectro de RMN- ${ }^{1} \mathrm{H}(400 \mathrm{MHz}$, $\left.\mathrm{DMSO}_{\mathrm{d} 6}\right)$ do composto apresentou um singleto em $\delta 13,06$ correspondente à hidroxila quelatogênica em C-5 e dois singletos em $\delta 10,74$ e 10,25, atribuídos às hidroxilas em C-7 e C-4', respectivamente, como também sugerido pelos deslocamentos batocrômicos observados no espectro de UV, quando da adição de $\mathrm{NaOH}$. O par de dubletes centrados em $\delta$ 8,07 (H-2' e H-6') e 6,94 (H-3' e H-5') com constante de acoplamento para protons orto relacionados $(J=8,98 \mathrm{~Hz})$ e integração para dois hidrogênios cada, estabelece o padrão de substituição de anel B para-dissubstituído, o que foi confirmado pelos acoplamentos observados no espectro de COSY. Ainda na região de aromáticos são observados dois singletos, um em $\delta 6,67$ que é característico do $\mathrm{H}-3$ de flavonas (MOREIRA et al., 2003) e outro em $\delta 6,16$, que poderia ser atribuído ao hidrogênio $\mathrm{H}-6$ ou H-8 do anel $A$. Sinais entre $\delta 5$ e 3 indicam a presença de uma unidade açúcar na molécula, que poderia estar ligada em C-6 ou C-8.

Os prótons da porção açúcar foram identificados com o auxílio dos espectros de correlação homonuclear ${ }^{1} \mathrm{H}-{ }^{-1} \mathrm{H}$ (COSY) e heteronuclear ${ }^{1} \mathrm{H}-{ }^{13} \mathrm{C}$ (HMQC). Um dublete centrado em $\delta 4,73 \mathrm{com}$ $J=8,9 \mathrm{~Hz}$, típico para acoplamento trans-diaxial (WILLIAMS; FLEMING, 1997), foi atribuído ao próton do carbono anomérico $\mathrm{H}-1$ ", estando o mesmo correlacionado com o sinal em 74,9 ppm atribuído ao C-1". Este sinal apresentou acoplamento com o multiplete em $\delta 3,88(\mathrm{~J}=8,9 \mathrm{~Hz})$, assinalado para H-2", e este mostrou acoplamentos trans-diaxial com os prótons em C-1" e C-3" $(\delta 3,29,1 \mathrm{H}, J=2,9 \mathrm{~Hz})$, como também um acoplamento à longa distância com $\mathrm{H}-4$ ", representado pelo quinteto centrado em $\delta 3,57$. Este sinal, devido à correlação com o multiplete em $\delta 3,81$, possibilitou a identificação de H-5". Não foi evidenciado neste espectro, um sinal para H-6" metileno,

Rev. Bras. Farmacogn., V. 13, n. 2, jul.-dez. 2003. 
que poderia ser atribuído ao sinal em $\delta 3,39$. Esses sinais apresentados para a porção glicosídica, aliados aos dados da literatura, sugerem a estrutura da glucose para a porção glicosídica.

Restou, portanto, determinar se a posição da porção açúcar está ligada ao C-6 (isovitexina) ou ao C-8 (vitexina) para a identificação do composto. Levando em consideração os deslocamentos químicos do próton anomérico $(\delta 4,73)$ e o do sinal de ${ }^{13} \mathrm{C}-\mathrm{RMN}$ em 105,4 ppm, não existe dúvida tratar-se de um $C$-glicosídeo. A determinação da posição da porção glicosídica foi definitivamente confirmada, em um espectro de HMBC, pelas correlações de longa distância $\left({ }^{2} \mathrm{~J}\right.$ e ${ }^{3} \mathrm{~J}$ ) entre o próton anomérico e os carbonos do anel A da estrutura flavonoídica apresentando, principalmente, correlação com o sinal em 157,8 ppm assinalado para C-9 (EL-MOUSALLAMY et al., 2000). Dessa forma, foi possível atribuir a estrutura da vitexina (1) a este composto, isolada, pela primeira vez, desta espécie vegetal.<smiles>O=c1cc(-c2ccc(O)cc2)oc2c(C3OC(CO)C(O)C(O)C3O)c(O)cc(O)c12</smiles>

(1) Estrutura da vitexina

\section{Identificação do galato de metila}

O segundo composto isolado apresentou espectro de $\mathrm{RMN}-{ }^{-1} \mathrm{H}\left(400 \mathrm{MHz}, \mathrm{DMSO}_{\mathrm{d} 6}\right)$ com apenas dois singletes em $\delta 3,79$ e 6,98. O espectro de UV mostrou bandas em $\lambda_{\max }(\mathrm{MeOH}) 273$ e $302 \mathrm{~nm}$, sugerindo a presença de um cromóforo aromático. O sinal em $\delta 3,79$ pode ser atribuído para grupos $-\mathrm{OCH}_{3}$ de ésteres metílicos ou metoxilas ligadas a anel aromático. Esse sinal, com integral para $3 \mathrm{H}$, quando comparado com o singlete em $\delta 6,98$ com integral de $2 \mathrm{H}$, indica a presença de dois prótons simétricos em anel aromático, sugerindo a estrutura do composto galato de metila (2), já isolado desta espécie (MEYRE-SILVA et al., 2001).<smiles>CC(=O)c1cc(O)c(O)c(O)c1</smiles>

(2) Estrutura do galato de metila 


\section{Identificação do hexatriacontano}

O terceiro composto isolado, p.f. $64-65^{\circ} \mathrm{C}$, quando analisado por CG-EM, mostrou $100 \%$ de um único pico em CG, cujo espectro de massa apresentou íon molecular $M^{+\cdot}$ a $m / z 506$, com fragmentação característica de hidrocarboneto linear, com perdas sucessivas de 14 u.m.a. $(\mathrm{m} / \mathrm{z}$ $43,57,71,85,99,113,127,141,155,169,183,197)$. O espectro de RMN-1H $\left(200 M H z\right.$, DMSO$\left._{-}\right)$ mostrou: um singlete largo e intenso em $\delta 1,25$ representando uma larga cadeia de $\mathrm{CH}_{2}$ e um triplete em $\delta 0,88$ atribuído ao $\mathrm{CH}_{3}$ terminal. Esses dados sugerem a estrutura do hidrocarboneto de cadeia longa de fórmula molecular $\mathrm{C}_{36} \mathrm{H}_{74}$ : hexatriacontano (3).

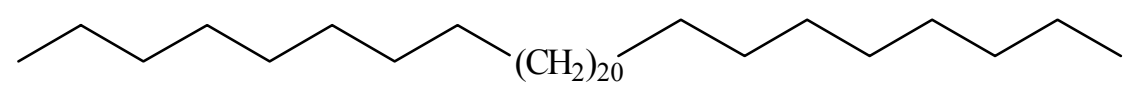

(3) Estrutura do hexatriacontano

\section{AGRADECIMENTOS}

Ao Dr. Gert Guenther Hatschbach, do Museu Botânico Municipal de Curitiba, pela identificação da planta e à Companhia Paranaense de Energia Elétrica (COPEL-PR) pelo apoio financeiro.

\section{REFERÊNCIAS BIBLIOGRÁFICAS}

ARMAREGO, W. L. F.; PERRIN, D. D. Purification of laboratory chemicals. $4^{\text {th }}$ ed. Oxford: Butterworth Heinemann, 2000.529p.

EL-MOUSALLAMY, A. M. D.; HUSSEIN, S. A. M.; MERFORT, I.; NAWWAR, A. M. Unusual phenolic glycosides from Cotoneaster orbicularis. Phytochemistry, v.53, n. 6, p. 699-704, 2000.

FORTUNATO, R. H. Revision del genero Bauhinia (Cercideae, Caesalpinioideae, Fabaceae) para la Argentina. Darwiniana, v. 27, n. 1-4, p. 527-557, 1986.

GONZALEZ-MUJICA, F.; MOTTA, N.; MÁRQUEZ, A. H.; CAPOTE-ZULUETA, J. Effects of Bauhinia megalandra aqueous leaf extract on intestinal glucose absorption and uptake by enterocyte brush border membrane vesicles. Fitoterapia, v. 74, n. 1-2 , p. 84-90, 2003.

MABRY, T. J.; MARKHAM, K. R.; THOMAS, M. B. The systematic identification of flavonoids New York: Springer-Verlag, 1970. 354 p.

MEYRE-SILVA, C.; YUNES, R. A.; MONACHE, F. D.; SANTOS, A. R. S.; SCHMELING, L. O.; GADOTTI, F. L.; CECHINEL-FILHO, V. Phytochemical and pharmacological analysis of Bauhinia microstachya (Raddi) Macbr., Leguminosae. Z. Naturforsch, v. 56c, p. 939-942, 2001.

MOREIRA, F. P. M.; COUTINHO, W.; MONTANHER, A. B. P.; CARO, M. S. B.; BRIGHENTE, I. M. C.; PIZZOLATTI, M. G. Flavonoides e triterpenos de Baccharis pseudotenuifolia - bioatividade sobre Artemis salina. Química Nova, v. 26, n. 3, p. 309-311, 2003.

PEPATO, M. T.; KELLER, E. H.; BAVIERA, A. M.; KETTELHUT, I. C.; VENDRAMINI, R. C.; BRUNETTI, I. L. Anti-diabetic activity of Bauhinia forficata decoction in streptozotocin-diabetic rats. Journal of Ethnopharmacology, v. 81, p. 191-197, 2002.

SILVA, F. R. M. B.; SZPOGANICZ, B.; PIZZOLATTI, M. G.; WILLRICH, M. A. V.; SOUZA, E. Acute effect of Bauhinia forficata on serum glucose levels in normal and alloxan-induced diabetic rats. Journal of Ethnopharmacology, v. 83, n. 1-2, p. 33-37, 2002. 
SILVA, K. L.; CECHINEL-FILHO, V. Plantas do gênero Bauhinia: composição química e potencial famacológico. Química Nova, v. 25, n. 3, p. 449-454, 2002.

VOLPATO, G. T.; DAMASCENO, D. C.; CALDERON, I. M. P.; RUDGE, M. V. C. Study of Bauhinia forficata L. extract on diabetes in pregnant rats. Revista Brasileira de Plantas Medicinais, v.2, n.1, p.49-55, 1999.

WILLAIN-FILHO, A. E.; BREVIGLIERI, E.; CECHINEL-FILHO, V.; SANTOS, R. S. Antinociceptive effect of the hydroethanolic extract of Bauhinia splendens stems in mice. Journal of Pharmacy and Pharmacology, v.49, p. 823-827, 1997.

WILLIAMS, D. H.; FLEMING, I. Spectroscopic methods in organic chemistry. $5^{\text {th }}$ ed. London: McGraw-Hill, 1997. 329p.

Prof. Dr. Cid Aimbiré Moraes dos Santos

Laboratório de Farmácia

Departamento de Farmácia - UFPR

Rua Prefeito Lothário Meissner, 3400

80210-170 - Curitiba - PR

e-mail: cid@ufpr.br 